\title{
Correction to: Colonization and habitat selection of a declining farmland species in urban areas
}

\author{
Martin Mayer $^{1} \cdot$ Peter Sunde $^{1}$ \\ Published online: 23 May 2020 \\ (C) Springer Science+Business Media, LLC, part of Springer Nature 2020
}

\section{Correction to: Urban Ecosyst (2020) 23(3):543-554 \\ https://doi.org/10.1007/s11252-020-00943-1}

In our paper, using distance sampling, we estimated the population density of hares in Aarhus city to 6.8 hares $/ \mathrm{km}^{2}$. By mistake, we corrected our initial estimate by removing the area occupied by buildings $(15 \%)$ when calculating the 'corrected' hare density, arguing that this area cannot be utilized by hares. This approach was erroneous, because the estimate obtained from the density function did not omit the area of buildings. The initially reported 'corrected' estimate of 8.2 hares $/ \mathrm{km}^{2}$ therefore slightly overestimated the hare density.

To correct this mistake, we now reduced the hare population estimate by the proportion of area covered by buildings (that cannot be utilized by hares), which led to a slightly lower population estimate of 492 hares and a population density of 5.7 hares $/ \mathrm{km}^{2}$ (instead of the previously estimated 8.2 hares/ $\mathrm{km}^{2}$ ). Importantly, this difference does not affect the findings and discussion of our study as this estimate is still comparable to agricultural areas in Denmark and other pastoral areas in Europe.

The online version of the original article can be found at https://oi.org/ 10.1007/s11252-020-00943-1

Martin Mayer

martin.mayer@bios.au.dk

1 Department of Bioscience, Aarhus University, Grenåvej 14,

8410 Rønde, Denmark 